\title{
Marco jurídico de la utilización de videoconferencia en materia penal
}

\author{
Legal Framework of the Use of Videoconference in Criminal \\ Matter
}

JORGE ALBORNOZ BARRIENTOS

Egresado de derecho, Chile

MARKO MAGDIC

Abogado, Chile

RESUMEN En la siguiente investigación presentamos un breve análisis de legislación internacional y comparada que habilita la utilización de videoconferencias como medio de cooperación internacional en materia penal. Se exponen algunos casos de países europeos y sudamericanos, como también un breve estudio del contexto jurídico chileno. Las fuentes utilizadas son principalmente documentos de trabajo, antecedentes jurisprudenciales y normativa interna de cada país.

PALABRAS CLAVE Videoconferencia, cooperación internacional, protección de víctimas y testigos, globalización, criminalidad transnacional.

ABSTRACT In the following research, we introduced a brief analysis of international and comparative law that enables the use of Videoconference as media for International Cooperation in Criminal Matters. Exposed some cases of European and South American countries, as well as a brief study of the Chilean legal context. The sources used are mainly working papers, judicial precedents and internal regulations of each country. 
ABSTRACT Videoconference, international cooperation, protection of victims and witnesses, globalization, international criminality.

Los mismos medios tecnológicos que fomentan la mundialización

y la expansión transnacional de la sociedad civil, también proporcionan la infraestructura para ampliar las redes mundiales de la sociedad 'incivil', vale decir, la delincuencia organizada, el tráfico de drogas, el lavado de dinero y el terrorismo.

Kofi A. AnNAN

\section{INTRODUCCIÓN}

En la actualidad, a la videoconferencia se le reconocen diversos usos y virtudes en el ámbito de la persecución penal, entre los cuales destaca su importancia en la mejor gestión de recursos. La utilización de esta herramienta puede disminuir considerablemente el número de audiencias suspendidas o de procedimientos abandonados por la falta de ratificación de los cargos como consecuencia de la imposibilidad de los testigos o de las víctimas de concurrir a declarar al lugar de realización del juicio. Asimismo, se economizan recursos al no tener que montar grandes operativos, por ejemplo, cuando tiene que trasladarse a un imputado fuera del centro de reclusión para que declare en algún procedimiento en el que participe, ya sea como testigo, informante o, incluso, como autor.

Asimismo, la utilización de este sistema contribuye al mayor y mejor cumplimiento de variados fines dentro del proceso penal, como la protección de testigos y víctimas que muchas veces, producto del temor que les infunde tener que encontrarse con un agresor, deciden abandonar el proceso o poner obstáculos para su participación en él. ${ }^{1}$ En definitiva, su utilización permite acortar la brecha entre la disponibilidad de medios

\footnotetext{
I. Refiriéndose a casos de denuncias a menores por violencia en el ámbito doméstico, en que una declaración frente al agresor pudiese producir temor a represalias, la profesora María Teresa Nevado sostiene que «en no pocas ocasiones el denunciante se retracta, y en el acto del juicio se acoge su derecho a no declarar, y ni siquiera solicita medida cautelar alguna. Este mal podría ser reducido estadísticamente si se ofreciera a la víctima la posibilidad de declarar desde otra sala, por medio de videoconferencia o cualquier otro medio electrónico válido» (20I2: I4).
} 
tecnológicos de que disponen, por una parte, los entes persecutores y, por otra, las organizaciones delictivas transnacionales.

En ese contexto, sus virtudes se han reconocido en buena parte de la normativa internacional y comparada, como también en abundante jurisprudencia, sin perjuicio de que resulta difícil encontrar alguna obra que estudie disposiciones internacionales que permitan su utilización como herramienta de cooperación internacional o, en su defecto, normativa comparada que sea de utilidad al momento de solicitar la realización de la diligencia.

Precisamente, con este artículo pretendemos entregar a autores e intervinientes en el proceso penal, un estudio que sirva de referencia para nuevas investigaciones, ya que al menos bajo la perspectiva de su uso internacional este tema no ha sido tratado en ningún cuerpo de doctrina jurídica de amplia circulación.

Así las cosas, producto de la mencionada falta de material doctrinario, la bibliografía utilizada para la elaboración de esta investigación consiste principalmente en documentos de trabajo más bien técnicos (ponencias, discursos, conferencias, reuniones de coordinación entre ministerios públicos, etcétera). Así también, se expondrá sobre la normativa comparada e internacional, haciendo referencia a tratados internacionales vinculantes en Chile, por ser el país de origen de la presente investigación, como a otros en el círculo europeo que se refieren expresamente a esta herramienta.

Respecto del derecho comparado sudamericano, se expondrán antecedentes extraídos de fuentes directas de los ministerios públicos respectivos, relativos a su legislación interna, fallos de sus tribunales de justicia y antecedentes de la experiencia de sus Estados. Para esto, se recurrirá a las respuestas del Cuestionario de Salvador de Bahía, que es un instrumento de trabajo de la Asociación de Ministerios Públicos del Mercosur. Precisamente, en el último apartado del presente artículo se expondrán los resultados entregados por la representación de la Fiscalía Nacional de Chile.

Realizado dicho análisis, y pudiendo llegar a una conclusión respecto del estado de la cuestión en materia de cooperación internacional, se expondrán las perspectivas generales que pueden preverse sobre esta herramienta, esperando fortalecer aún más la idea de que con la utilización de la videoconferencia no sólo no se vulneran ninguno de los derechos 
de los intervinientes en el Proceso Penal, sino que, muy por el contrario, muchas veces se garantizan en mayor y mejor medida.

\section{ANÁLISIS Y DEFINICIÓN DEL TÉRMINO VIDEOCONFERENCIA}

Se ha afirmado por la doctrina que «la videoconferencia es un sistema de comunicación interactivo que transmite simultáneamente la imagen, el sonido y los datos, permitiendo una comunicación bidireccional plena, en tiempo real, de tal manera que se posibilita un mismo acto o reunión a la que asisten personas que se encuentran en lugares diferentes» (Monterde, 2006). ${ }^{2}$

No obstante estar de acuerdo con dicha afirmación, consideramos que para convenir una definición más completa deben agregarse algunos elementos que aquella omite. Por una parte, debe entenderse como videoconferencia no sólo al sistema que permite una reunión a distancia, sino que también a la reunión en sí misma. Así también debe entenderse que una videoconferencia puede ser bidireccional, en donde existen dos puntos distantes que se comunican, o multidireccional, como veremos.

\section{INTERPRETACIONES DEL TÉRMINO VIDEOCONFERENCIA}

Interpretación amplia. Una idea general del concepto videoconferencia es posible derivarla del desglose de la propia palabra, entendiendo como primera aproximación que se trata de una conferencia realizada por medio de video.

Sin embargo, entendiendo videoconferencia como concepto amplio, en primer lugar debemos advertir que «la palabra 'teleconferencia' está formada por el prefijo 'tele' que significa distancia, y la palabra 'conferencia' que se refiere a encuentro, de tal manera que combinadas establecen un encuentro a distancia» (Vásquez, 2009: 5).

A su vez, entre teleconferencia y videoconferencia existiría una relación de género y especie. De tal manera, debemos entender a la videoconferencia como una especie de encuentro a distancia, que cuenta

2. Monterde cita a De la Mata, en su ponencia denominada «La utilización de la videoconferencia en las actuaciones judiciales», presentada en el Seminario de Formación Continuada del CGPJ, realizado en Madrid, del I7 al I9 de septiembre del 2003. 
con la particularidad de llevarse a cabo mediante un dispositivo de video y audio, el que a través de una conexión bidireccional o multidireccional permite que dos o más personas puedan verse y oírse simultáneamente. ${ }^{3}$

Así, podemos apreciar que puede tratarse de una conexión bi o multidireccional, puesto que a través de videoconferencia pueden comunicarse dos o más partes. Si bien conceptualmente podría aceptarse la idea de que exista una videoconferencia unidireccional, veremos que por los principios del proceso penal, que exigen la posibilidad de contradicción de los declarantes, en este ámbito no será admisible la declaración por medio de video y audio de una sola parte.

Asimismo, debemos destacar que lo que diferencia a una videoconferencia de, por ejemplo, una llamada telefónica, es que en la primera cada una de las partes que en ella participan puede apreciar la imagen de las otras, lo que resulta de extrema importancia si consideramos que la gran mayoría de los mensajes que se perciben en una conversación presencial forman parte de lo que se denomina comunicación no verbal. ${ }^{4}$

Para graficar la importancia que esto tendría para un sistema procesal penal, imaginemos la diferencia que constituiría producir una prueba mediante la lectura de la declaración de un testigo versus la posibilidad de interrogarlo directamente. Por ejemplo, en el caso del interrogatorio a una víctima de abuso sexual, en el cual el correlato emocional a la declaración constituye parte importante del grado de convicción al que llegue el tribunal.

En Chile, nuestras magistraturas se han referido al respecto sosteniendo:

3. «La utilidad de servir de conexión a distancia, en tiempo real, explica que uno de los campos donde más se ha propiciado el uso de este nuevo instrumento sea la asistencia jurídica internacional». Fuente: Documento de trabajo para el «I Taller sobre Uso de la Videoconferencia en la Cooperación Jurídica Internacional», celebrado en la Fiscalía General del Estado de Paraguay, el día 28 de abril de 2009, en la ciudad de Asunción.

4. Al respecto, cabe citar al psicólogo y profesor emérito de psicología (UCLA) Albert Mehrabian, quien sostiene que, en ciertas ocasiones, como por ejemplo cuando las personas hablan sobre lo que están sintiendo, solamente el $7 \%$ de lo que comunican es transferido por el significado de las palabras, mientras que otro $38 \%$ proviene de la entonación o forma con que estas palabras son dichas. El $55 \%$ restante se transmite mediante señales visuales, es decir, lenguaje corporal (Mehrabian, I972). 
En efecto, el tribunal apreció la prueba directa de la existencia del delito, constituida por el atestado del menor de iniciales J.I.R.T., quien a través del circuito de videoconferencia entregó al tribunal un relato hilado, pormenorizado, acabado, ubicado en tiempo y espacio, el cual iba acompañado de un correlato emocional compatible a los hechos que explayaba. El menor víctima pudo transmitir al tribunal los episodios vividos durante su convivencia al cuidado de su padre no sólo en forma verbalizada, sino que incluso pudo gesticular con sus manos a qué era obligado a hacer, al tiempo que era capaz de describirlo con palabras. De esta forma, el tribunal se cercioró que existe en el relato del menor, además de las características ya mencionadas, una coherencia entre lenguaje verbal, el corporal [...] y el emocional (un notorio cambio del estado emocional en los momentos en que éste se refería a cuestiones generales introductorias de su relato a aquellos en los que hacía referencia al episodio abusivo). ${ }^{5}$

Sistema de videoconferencia. Además de denominarse videoconferencia a una «especie de reunión» a distancia, tal como se expuso más arriba, se le da la misma calificación al «sistema» que permite que ésta se realice.

De esta forma, encontramos que en la segunda de las mencionadas acepciones, se entiende que «la videoconferencia consiste básicamente en un sistema interactivo de comunicación que transmite simultáneamente y 'en tiempo real' la imagen, el sonido y los datos a distancia, permitiendo relacionar a un grupo de personas situadas en dos o más lugares distintos como si la reunión y el diálogo se sostuviese en el mismo lugar» (Tirado, s/f: 4).

\section{TIPOS DE SISTEMAS DE VIDEOCONFERENCIAS}

Dentro de la concepción de videoconferencia, entendida como sistema de conexión a distancia, podemos encontrar distintos tipos, los que a su vez harán variar diferentes factores en su utilización, como lo son la distancia a la que se podrá celebrar una reunión, calidad de la imagen, seguridad y privacidad en las comunicaciones y costos para su utilización. A estos distintos tipos de sistemas pasaremos revista brevemente.

5. 7. ${ }^{\circ}$ Tribunal de Juicio Oral en lo Penal de Santiago, Chile, causa RIT 246-2007, analizado junto a otra jurisprudencia chilena en Albornoz y Magdic (20I2). 
Circuito cerrado de televisión. Consiste en que en lugares ubicados a escasa distancia (como por ejemplo dos salas de juicio oral, ubicadas una al lado de la otra) se forma una línea de video a través de cableado, que permite que se transmita entre ellos lo que está sucediendo en ambos simultáneamente. ${ }^{6}$

Método IP (Internet Protocol). ${ }^{7}$ "Utilizando Internet, procedimiento de videoconferencias utilizando el Video Phone y la conexión a Internet, además del software y el equipamiento adecuado» (Vásquez, 2009: 2).

Cabe señalar que, si bien mediante este sistema se obtiene una videoconferencia de manera prácticamente instantánea, y con un bajísimo costo, podrían producirse problemas tanto de conectividad como de lentitud y distorsión de imagen y/o sonido. Esto debido a que su utilización depende de la capacidad de ancho de banda y de la congestión de la línea utilizada en dicho momento.

Como precedente, cabe mencionar que «la aplicación del software y servicio propietario Skype fue empleada por primera vez en febrero de 20 I I en Estados Unidos (caso de tráfico de drogas en el Estado de Georgia en que el abogado defensor del acusado, Arturo Corso, solicitó

6. Este sistema se utiliza, por ejemplo, en el derecho inglés, cuando «el testigo es un niño que comparece en un caso relativo a una infracción sexual o de violencia, puede declarar en una sala contigua a la de audiencias y su declaración será retransmitida por video» (Delmas-Marty, 2000: I75). Asimismo, puede sostenerse la posibilidad de utilizar dicha modalidad en el ordenamiento jurídico chileno, en virtud del universalmente aceptado principio del interés superior del menor, complementando así lo dispuesto en el artículo 3 Io de nuestro Código Procesal Penal, que dispone que «el testigo menor de edad sólo será interrogado por el presidente de la sala, debiendo los intervinientes dirigir las preguntas por su intermedio».

7. IP (Internet Protocol): Protocolo de Internet. Es el conjunto de estándares tecnológicos y especificaciones técnicas que permiten que la información sea transmitida de una red a otra a través de todo Internet. Es el mecanismo por el cual la red intercambia datos. Por ejemplo, IP es el mecanismo de entrega por el cual un correo se envía a través de la red. IP define cómo los datos serán divididos en paquetes; cada paquete es codificado con una dirección IP; y varios paquetes constituyen un único mensaje. Estos paquetes viajan a lo largo de Internet por diferentes rutas y llegan a su destino en un orden revuelto. Se necesita un segundo protocolo, TPC (Transmisión Control Protocolo), para volver a poner estos paquetes en orden. Es en esencia la forma en la que Internet trabaja (véase <http://www.sindicacion.net/diccionario_glosario/ diccionario_i.htm>). 
al juez y consiguió que se realizara declaración por Skype de un testigo que se encontraba en Texas) (Nevado, 2012: I2).

De todas formas, dichos problemas podrían solucionarse, o al menos mitigarse, si se contara con una línea exclusivamente dedicada a la práctica de la videoconferencia.

Método ISDN (Integrated Services Digital Network). Conocido también como RDSI, por la traducción de su sigla en español (Red Digital de Servicios Integrados), es un conjunto de estándares de comunicaciones que permiten un único cable o fibra óptica para transportar voz, servicios de red digital y video, en una conexión rápida dedicada a la transmisión de datos. Ésta se puede utilizar para tener acceso a Internet o a una videoconferencia, en donde «la comunicación se produce en condiciones excelentes de seguridad, celeridad y calidad, gracias a la encriptación y a la elevada capacidad de los canales de transmisión que se utilizan» (Tirado, s/f).

El ISDN es la evolución de la línea telefónica normal y presenta como gran diferencia que además de la señal de voz tradicional puede transportar otro tipo de datos, entre los cuales se puede considerar la imagen de la videoconferencia.

Cabe destacar que en este sistema «las señales de audio y video que se intentan transmitir, se encuentran por lo general en forma de señales analógicas, por lo que para poder transmitir esta información a través de una red digital, ésta debe ser transformada mediante algún método a una señal digital, una vez realizado esto, se deben comprimir y multiplexar estas señales para su transmisión. El dispositivo que se encarga de este trabajo es el codec, que en el otro extremo de la red realiza el trabajo inverso para poder desplegar y reproducir los datos provenientes del punto remoto» (Vásquez, 2009: I6). Es decir, el codec es el codificador y decodificador que se encarga de transformar las señales de audio y video analógicas en digitales en el punto de envío, y viceversa en el punto de llegada.

\section{RESUMEN COMPARATIVO}

Analizadas las ventajas y desventajas de estos sistemas, podemos resumir que si se cuenta con una conexión IP de alta velocidad, es preferible su utilización para llevar a cabo una videoconferencia, producto de que si 
bien el sistema de circuito cerrado de televisión tiene menores costos y mayor confiabilidad y seguridad, éste es demasiado limitado en cuanto a alcance, lo que lo hace lisa y llanamente inutilizable para una videoconferencia internacional.

Asimismo, si comparamos entre los sistemas IP e ISDN, encontramos que si bien ambos tienen un alcance ilimitado mientras se cuente con los equipos necesarios, su disponibilidad depende de la existencia de una línea ISDN, mientras que para la utilización de IP basta con una línea telefónica, que en la actualidad puede encontrarse en la mayor parte de los países medianamente desarrollados.

Respecto a la seguridad, el sistema ISDN es más confiable que el sistema IP, pero menos que el circuito cerrado de televisión. Respecto de los costos de llevar a cabo una videoconferencia mediante el sistema ISDN, estos muchas veces derivan en cifras astronómicas, mientras que para el sistema IP solamente debe considerarse la contratación permanente de una línea telefónica de alta velocidad. Esto hace que aún siendo más segura la conexión mediante la primera de estas vías, sea muy preferible la utilización de la segunda.

Por todo esto, parece evidente que el sistema más eficiente para utilizarse en una videoconferencia internacional es el IP, aun cuando requiera de una línea de alta velocidad.

\section{CARACTERÍSTICAS DE LA VIDEOCONFERENCIA}

Según todo lo dicho, compartimos la opinión de que, en lo principal, la videoconferencia se caracteriza por ser:

- Integral, ya que permite el envío de imagen (personas, video, multimedia, etcétera), sonido (voz de alta calidad, música, etcétera) y datos (ficheros automáticos, bases de datos, etcétera).

- Interactiva, pues permite una comunicación bi o multidireccional en todo momento.

- Sincrónica, es decir, en tiempo real, pues transmite en vivo y en directo, desde un punto a otro o entre varios puntos a la vez (Tavolari, 2003: IO-II). 
Finalmente, teniendo en cuenta las distintas acepciones del concepto de videoconferencia, como sus características, podemos proponer una definición que podamos utilizar para el presente trabajo, y en donde se agreguen los requisitos esenciales de cada una de las definiciones expuestas.

De esta forma, podríamos decir que «la videoconferencia es una especie de reunión a distancia de dos o más personas, efectuada gracias al sistema tecnológico del mismo nombre, el cual produce un intercambio bi o multidireccional de imagen y sonido, permitiendo una comunicación en tiempo real y prácticamente en las mismas condiciones que se darían si los interlocutores estuviesen en el mismo punto geográfico» (Albornoz y Magdic, 201 2: 38).

\section{NORMATIVA INTERNACIONAL SOBRE LA UTILIZACIÓN DE VIDEOCONFERENCIA EN MATERIA PENAL}

Como se mencionó, existen numerosas razones que legitiman y justifican el uso de la videoconferencia como medio de cooperación internacional en materia penal, y precisamente es por sus virtudes, y por tanto beneficios que entrega a la comunidad internacional, que estas razones han sido recogidas en los textos internacionales de derecho público y en las regulaciones internas de derecho comparado que prevén su uso.

Así, el uso de la videoconferencia ha sido previsto en las legislaciones de numerosos países, mientras que en muchos otros se viene practicando conforme a habilidades genéricas de uso de las nuevas tecnologías y admisiones jurisprudenciales específicas. Por ejemplo, en «la mayoría de los países europeos la utilizan normalmente en los procesos judiciales. [Mientras que] en Latinoamérica su uso es cada vez más frecuente y con resultados altamente satisfactorios» (Candia, 2009).

Asimismo, puede apreciarse un amplio número de tratados internacionales que reconocen el uso de la videoconferencia como medio de cooperación internacional en materia penal. De todos éstos se expondrán aquellos considerados como más paradigmáticos e importantes.

Por su parte, aquellos que no la reconocen expresamente, sí consagran el derecho a la defensa, plasmando principios que no sólo no constituyen un obstáculo para su uso sino que muy por el contrario, sientan 
directrices y constituyen derechos que en muchos casos pueden respetarse más cabalmente gracias a esta herramienta tecnológica.

COHERENCIA ENTRE LOS PRINCIPIOS RECTORES DEL PROCESO PENAL CONSAGRADOS EN TRATADOS INTERNACIONALES Y LA UTILIZACIÓN DE VIDEOCONFERENCIA COMO MEDIO DE COOPERACIÓN INTERNACIONAL

El derecho al debido proceso es reconocido por los tratados internacionales con mayor relevancia a nivel mundial, ocurriendo lo mismo con el derecho a la defensa jurídica. Ambos se concretizan en procedimientos penales regidos por principios que perfectamente pueden legitimar la utilización de la videoconferencia en el marco del proceso penal. Dentro de éstos, encontramos por ejemplo principios como los de inmediación y contradicción.

Inmediación. El principio de inmediación exige que el tribunal haya percibido por sí mismo la producción de la prueba, y aquí «parece conveniente apuntar que la inmediación — sustantivo compuesto, integrado por un prefijo 'in' y un núcleo 'mediación'- expresa, positivamente, la idea de una vinculación directa, vale decir, sin el tamiz de cosas ni de personas, [en definitiva] ausencia de intermediarios» (Tavolari, 2003: 6).

«Desde luego la inmediación no necesariamente es o debe ser absoluta, porque aunque se trate de un juicio oral, es posible introducir ciertos elementos de prueba por lectura o exhibiéndolos (fotografías, planos, etcétera)» (Chahuán, 2007: 283), ya que en realidad este principio «apunta a la aprehensión sensorial directa por el juez, de la información que emana de los órganos de prueba» (Tavolari, 2003: 6). De esta forma, respecto de la percepción directa por parte del juez, «si ésta comprende tanto la inmediata - física - como la mediata —intermediada por un mecanismo audiovisual-, entonces sería dable sostener que la declaración testimonial prestada a través de videoconferencia respeta el principio de inmediación, en la medida que el Tribunal puede mirar y escuchar [al declarante]» (Ministerio Público, 2003: 208).

Aquí, cabe hacer hincapié en que lo que más se busca con la consagración de este principio: evitar la reproducción del nefasto panorama que se daba en los procedimientos penales de antaño (aún vigentes en algunos países), donde a través de un funcionario judicial, el juez recibía una apreciación muchas veces parcial y subjetiva de la información 
producida a través de los medios probatorios y de la confrontación de la prueba, además de posibilitar en mucho mayor medida una eventual corrupción. ${ }^{8}$

La idea principal, entonces, es que toda persona tenga derecho al acceso directo ante el tribunal, sin intermediarios de ningún tipo.

En tal sentido se reconoce en la Declaración Universal de los Derechos Humanos, cuyo artículo so prescribe que «toda persona tiene derecho, en condiciones de plena igualdad, a ser oída públicamente y con justicia por un tribunal independiente e imparcial, para la determinación de sus derechos y obligaciones o para el examen de cualquier acusación contra ella en materia penal», principio que es recogido en similar redacción por el pacto de San José de Costa Rica en su artículo 8 núm. I, ${ }^{9}$ y por el Pacto Internacional de Derechos Civiles y Políticos en su artículo I 4 núm. I. ${ }^{10}$

Contradicción. "El principio contradictorio garantiza que la producción de las pruebas se hará bajo el control de todos los sujetos procesales, con la finalidad [de] que ellos tengan la facultad de intervenir en dicha producción, formulando preguntas, observaciones, objeciones, aclaraciones y evaluaciones, tanto sobre la prueba propia como respecto de la de los otros» (Chahuán, 2007: 286).

En ese sentido, la Convención Americana sobre Derechos Humanos, en su artículo $8 .^{\circ}$ núm. 2 letra f), reconoce el «derecho de la defensa a interrogar a los testigos presentes en el tribunal y de obtener la comparecencia, como testigos o peritos, de otras personas que puedan arrojar luz sobre los hechos». A su vez, el Pacto Internacional de Derechos Civiles y Políticos consagra en su artículo I4 núm. 3 letra e), el derecho «a interrogar o hacer interrogar a los testigos de cargo y a obtener la comparecencia de los testigos de descargo y que éstos sean interrogados en las mismas condiciones que los testigos de cargo».

8. Conocida es la figura del actuario, funcionario presente a lo largo de todo el antiguo proceso penal como lo conocimos en Chile, y que aún se utiliza para conocer y fallar causas sobre delitos cometidos con anterioridad a la entrada en vigencia del actual sistema.

9. «Toda persona tiene derecho a ser oída, con las debidas garantías y dentro de un plazo razonable, por un juez o tribunal competente.»

Io. «Toda persona tendrá derecho a ser oída públicamente y con las debidas garantías por un tribunal competente, independiente e imparcial, establecido por la ley, en la substanciación de cualquier acusación de carácter penal formulada contra ella.» 
Así, de la consagración en derecho internacional de los principios expuestos, puede percibirse que se reconoce el derecho de todas las personas a ser oídas por un juez o tribunal competente, como también a interrogar o hacer observaciones a las pruebas rendidas, quedando de manifiesto, atendida la naturaleza de los cuerpos jurídicos mencionados, que no se establece ni cómo debe ser oída la persona, ni en qué condiciones deben llevarse a cabo el interrogatorio cruzado y las observaciones a la prueba, sin perjuicio de las demás garantías existentes.

De esta forma, podemos apreciar que con la realización de la videoconferencia para las diligencias mencionadas, no se están vulnerando los derechos garantizados por estos tratados internacionales, sino que, muy por el contrario, en determinadas situaciones podrían protegerse en mayor y mejor medida. Por una parte, «el principio de contradicción no se vería afectado, puesto que la fiscalía como la defensa y el acusado pueden interrogar y contrainterrogar, respectivamente, al testigo desde la sala de audiencias, mediante la ventaja que importa el uso de tal sistema, cual es permitir estar en más de un lugar al mismo tiempo» (Ministerio Público, 2003: 208). Por la otra, el hecho de que el uso de videoconferencia permita que se realicen, por ejemplo, juicios orales que sin ella serían imposibles de llevar a cabo, contribuye a que se confirme el derecho con que cuentan las personas y se protejan con mayor efectividad.

RECONOCIMIENTO EXPRESO DE LA PRÁCTICA DE VIDEOCONFERENCIA EN NORMAS INTERNACIONALES

Como se adelantó, tal como podemos interpretar de los principales tratados internacionales de derechos humanos que la realización de videoconferencias en el marco del proceso penal es perfectamente válida, existen otros tratados, ciertamente más específicos y de aplicación eminentemente práctica, que tratan el tema de manera directa y expresa. Algunos de ellos, a saber:

Estatuto de la Corte Penal Internacional. ${ }^{11}$ Aprobado en el marco de la Convención de Roma el I7 de julio de I998, contempla en su artículo 69.2 la posibilidad de que el testigo preste testimonio "por medio de una grabación de video o audio» y en su artículo 68.2, habilita la

I I. Ratificado finalmente por Chile el 29 de junio del año 2009. 
presentación de pruebas «por medios electrónicos u otros medios especiales», cuando con esa medida se proteja a víctimas o testigos. Incluso, el artículo 63.2 admite esta posibilidad respecto de los acusados, en el evento de que estando presentes perturbaren constantemente la realización del juicio, pudiendo hacérseles salir de la sala donde se desarrolle el enjuiciamiento, observando el proceso y dándole instrucciones a su defensor desde fuera, «utilizando, en caso necesario, tecnologías de comunicación».

Convenio Europeo relativo a la Asistencia Judicial en Materia Penal. Aprobado el 29 de mayo de 2000 por el Consejo de Ministros de Justicia y Asuntos Exteriores de la Unión Europea, regula la práctica de las videoconferencias en su artículo io.

Dicho artículo, está destinado a sustentar y facilitar la utilización del sistema con vistas a superar las dificultades que pueden surgir en casos penales cuando una persona se encuentre en un Estado miembro y no sea oportuna o posible su comparecencia para ser oída en otro Estado miembro. En particular, este artículo establece disposiciones relativas a las solicitudes y a la realización de audiciones por videoconferencia, y se aplica en general a las audiciones de peritos o testigos, si bien, bajo determinadas condiciones que figuran en el apartado 9, puede aplicarse también a las audiciones de personas inculpadas. ${ }^{12}$

Convención Europea de Asistencia Mutua en Materia Penal. ${ }^{13} \mathrm{La}$ Convención Europea de Asistencia Mutua en Materia Penal fue suscrita en Estrasburgo el 20 de abril de 1959 por los miembros del Consejo de Europa y entró en vigor el I 2 de junio de I962. Asimismo, se han agregado dos protocolos (I978 y 200I), que buscan modernizar e implementar nuevas estrategias a la convención.

Su objeto es que los Estados partes se proporcionen la más amplia asistencia mutua en los procedimientos relativos a materias penales cuya

I2. Informe explicativo del Convenio, del 29 de mayo de 2000 , relativo a la asistencia judicial en materia penal entre los Estados miembros de la Unión Europea (texto aprobado por el Consejo el 30 de noviembre de 2000). Diario Oficial C 379 del 29 de diciembre de 2000 , pp. 7-29.

I3. El Decreto Supremo núm. I I 2 del Ministerio de Relaciones Exteriores de Chile, publicado el día 23 de marzo del año 20I2, promulga la Convención Europea de Asistencia Mutua en Materia Penal, su protocolo adicional y su segundo protocolo adicional, y dispone su vigencia desde esa misma fecha, con ciertas reservas. 
represión en el momento de pedir la asistencia sea de competencia de las autoridades judiciales del país requirente. Se excluyen expresamente: las detenciones, ejecución de condenas o delitos de carácter militar que no estén contempladas con arreglo al derecho penal común y ha sido modificada y complementada por dos Protocolos Adicionales, suscritos con posterioridad a la misma.

En el artículo 9 del segundo de sus protocolos (Estrasburgo, 8 de noviembre de 200I), se establece la posibilidad de realizar videoconferencias en los siguientes términos:

Si una persona estuviera en el territorio de una parte y tuviera que prestar testimonio como testigo o perito ante las autoridades judiciales de otra parte, esta última, cuando no sea conveniente o posible que la persona que deba prestar testimonio comparezca en persona en su territorio, podrá solicitar que la audiencia se realice mediante videoconferencia.

Esto, según lo dispuesto en los párrafos 2 a 7 del mismo protocolo, los que se refieren a las condiciones necesarias para poder llevar a cabo la videoconferencia, y a requisitos formales como autoridades que deberán estar presentes, antecedentes a acompañarse, costeo de la operación, etcétera.

Convención de las Naciones Unidas contra la delincuencia Organizada Transnacional. ${ }^{14}$ «La Convención de Palermo consta de 4I artículos, forma parte del derecho penal internacional y su importancia se debe a que, por primera vez, un instrumento penal internacional lograba unificar definiciones y establecer tipos penales en común para todos los Estados partes» (Granadillo, 2006). En su artículo 24, se exige a los Estados parte que adopten medidas apropiadas para una protección eficaz de testigos o de víctimas testigos en investigaciones de delitos materia de la Convención.

Entre las medidas pertinentes se reconoce la posibilidad de establecer normas probatorias que permitan las declaraciones sin hacer peligrar la seguridad de los testigos, dándose como ejemplo el uso para ello de diversa tecnología de la comunicación como videoconferencias y otras (Piedrabuena, 2005).

I4. Respecto de su vinculación, hasta marzo de 2009, ha sido firmada por I 47 Estados y, dentro de éstos, ha sido ratificada a lo menos por 93 de éstos. 


\section{RECONOCIMIENTO Y LEGITIMACIÓN JURÍDICA DE LA UTILIZACIÓN DE LA VIDEOCONFERENCIA EN EL DERECHO COMPARADO}

En este apartado se analizarán algunos casos europeos con la finalidad de conocer, al menos de modo preliminar, el estado de la videoconferencia en lo relativo a su utilización y legitimidad en el ámbito europeo continental, para posteriormente analizar la realidad sudamericana, principalmente en el marco de la Reunión Especializada de Ministerios Públicos del Mercado Común del Sur (en adelante, «REMP»), la que precisamente entrega el contexto para el análisis de las normativas comparadas de nuestros países vecinos.

\section{APROXIMACIONES AL CASO EUROPEO}

Además de los convenios vinculantes en la Unión Europea estudiados con anterioridad, que constituyen el derecho internacional atingente, también en materia de derecho comparado encontramos que importantes países han adoptado el sistema de videoconferencia como medio de cooperación internacional.

Italia. En este contexto, a Italia «corresponde el mérito de haber jugado un papel de país pionero en materia de regulación y uso de videoconferencia en el plano internacional, por motivo del art. I 6 de la ley 367 del 5 de octubre de 200I» (Tirado, s/f). Dicha normativa, fue la que finalmente incorporó a su Código Procesal Penal, como artículo 205 ter, el uso de la videoconferencia con países extranjeros para la audición de testigos y peritos, así como de inculpados en el extranjero que no puedan ser transferidos a Italia.

Portugal. Asimismo, y de acuerdo a Tirado (s/f), «en Portugal, tanto la Ley de Cooperación Judicial Internacional I44/99 [...], como el Código Procesal Penal —en sus arts. 3 I 7 y 3 I 8 en relación con el artículo I I I- contemplan la posibilidad de empleo de la videoconferencia» en materia internacional.

Francia. Idéntico es el caso de Francia, donde en el artículo 706-7 I de su Código Procesal Penal, se señala que «cuando las necesidades de la investigación lo justifiquen, la audición o el interrogatorio de una persona así como una confrontación entre varias personas pueden ser realizadas en distintos puntos del territorio de la República encontrándose conecta- 
dos por medios de comunicación». La misma norma agrega en el párrafo segundo que dichas disposiciones son aplicables a casos internacionales por motivos de solicitudes emanadas de autoridades judiciales extranjeras o de actos de cooperación realizados en el extranjero a solicitud de autoridades francesas (Tirado, $\mathrm{s} / \mathrm{f}$ ).

España. ${ }^{15}$ Finalmente, en el caso de España el artículo 229 de la Ley Orgánica del Poder Judicial, luego de reconocer los principios de oralidad, concentración e inmediación, prescribe en el núm. 3 de dicha disposición que, en este marco, las «actuaciones podrán realizarse a través de videoconferencia u otro sistema similar que permita la comunicación bidireccional y simultánea de la imagen y el sonido y la interacción visual, auditiva y verbal entre dos personas o grupos de personas geográficamente distantes, asegurando en todo caso la posibilidad de contradicción de las partes y la salvaguarda del derecho de defensa, cuando así lo acuerde el juez o tribunal». ${ }^{16}$

Ante el hecho de que ese artículo no prohíbe la realización de videoconferencia internacional, pero tampoco lo permite expresamente, es que dicha disposición se ha visto complementada con un elevado número de tratados de asistencia jurídica mutua con diversos países, como se da por ejemplo, en los casos de México, ${ }^{17}$ Colombia $^{18}$ y Brasil. ${ }^{19}$

I 5. Si bien nos referimos en términos generales, Nevado (20I2) realiza un análisis exhaustivo al respecto.

I6. Véase <http://noticias.juridicas.com/base_datos/Admin/lo6-I985.13t3.html\#cı >.

I7. Entra en vigencia con fecha 26 de julio de 2007 en los Estados Unidos Mexicanos, y su artículo I 8 está exclusivamente dedicado a la audiencia por videoconferencia (cf. Godoy, 2009).

I 8. «La ley I.I79 de fecha 3 I de diciembre de 2007, aprobó el Protocolo adicional al Convenio de Cooperación Judicial en materia penal entre la República de Colombia y el Reino de España — celebrado el 29 de mayo de I997- [...] que en su art. 6 núm. 2, prevé el uso de videoconferencia entre ambos Estados» (Godoy, 2009).

I9. «Con fecha 22 de mayo de 2006 , se celebró el convenio de cooperación jurídica y asistencia judicial en materia penal entre el Reino de España y la República Federativa de Brasil, en donde se estableció en forma expresa en el Capítulo III 'Formas de Asistencia', artículo I7 'Videoconferencia' que: 'Las partes podrán convenir en la obtención de declaración a través de videoconferencia con arreglo a las condiciones que se especifiquen en cada caso'» (Godoy, 2009). 
REALIDAD SUDAMERICANA SEGÚN EL CUESTIONARIO DE SALVADOR DE BAHÍA SOBRE VIDEOCONFERENCIA

Tal como se expuso en la parte introductoria del presente apartado, en éste se expondrán las normativas más relevantes del Cono Sur americano, para lo cual recurrimos eminentemente a los registros de la propia Reunión Especializada de Ministerios Públicos del Mercosur ${ }^{20}\left(\mathrm{REMPM}^{21}\right)$, y específicamente a su instrumento de trabajo denominado Cuestionario de Salvador de Bahía sobre Videoconferencias, ${ }^{22}$ el cual fue presentado y aprobado en la Reunión Preparatoria de la VI REMPM, en virtud de la proposición de la Delegación de Paraguay, la que «estimó pertinente revelar información referente al uso de dicha herramienta en los diferentes Ministerios Públicos, considerando la tendencia regional y la importancia de la implementación de la videoconferencia en la cooperación internacional». ${ }^{23}$

Argentina. ${ }^{24}$ Según las respuestas del Cuestionario de Salvador de Ba-

20. Que «surge de una decisión del Consejo del Mercado Común (CMC) del Mercosur reunido en la ciudad de Asunción el I9 de junio del año 2005 [...] por la necesidad de contar con un mecanismo ágil en el relacionamiento entre los Ministerios Públicos de los Estados Partes y Asociados, para lograr potenciar las acciones conjuntas para la prevención, investigación y represión del crimen organizado, narcotráfico y el terrorismo, entre otros» (disponible en <http://www.ministeriopublico.gov.py/reunion/pdf/rempm.pdf >).

2I. Cuenta con Estados partes (Argentina, Brasil, Paraguay, Uruguay y Venezuela) y Estados asociados (Bolivia, Chile, Colombia, Ecuador y Perú). Las REMPM se organizan semestralmente, tendiendo a una reunión preparatoria previa a cada una, y la organización es responsabilidad de la Presidencia pro tempore.

22. «Los objetivos de dicho cuestionario son: analizar la viabilidad técnica y jurídica de la implementación de la videoconferencia como medio probatorio; conocer en detalle sobre los aspectos prácticos y el marco jurídico que involucra el uso interno e internacional de la videoconferencia; e incentivar e incrementar el uso de la videoconferencia entre los Ministerios Públicos miembros y asociados del Mercosur.» Fuente: Documento de trabajo para el «I Taller sobre Uso de la Videoconferencia en la Cooperación Jurídica Internacional», celebrado en la Fiscalía General del Estado de Paraguay, el día 28 de abril de 2009, en la ciudad de Asunción.

23. Véase el Documento de trabajo para el «I Taller sobre Uso de la Videoconferencia en la Cooperación Jurídica Internacional», celebrado en la Fiscalía General del Estado de Paraguay, el día 28 de abril de 2009, en la ciudad de Asunción.

24. Cuestionario de Salvador de Bahía sobre Videoconferencia, respondido por Adrián O. Marchisio, Secretario de la Procuración General de la Nación Argentina. 
hía antes aludido, Argentina cuenta con equipos para realizar videoconferencias y utiliza tecnología IP, con propia infraestructura y «desde su implementación, en mayo de 2008 [y hasta la fecha de presentación del cuestionario, 28 de abril de 2009], no se habían realizado videoconferencias en la materia que nos interesa».

Respecto a la legislación atingente, «la Constitución Nacional —al incorporar el bloque normativo supranacional, art. 75, inciso 22- autoriza la posibilidad de realizar declaraciones judiciales mediante el sistema de videoconferencias, [ya que se encuentra incorporada en] el estatuto de la Corte Penal Internacional» ${ }^{25}$ y en la Convención contra la Delincuencia Organizada Transnacional, ${ }^{26}$ como asimismo existe un proyecto de ley iniciado por moción parlamentaria en la República de Argentina, elaborado por la Secretaría General de Coordinación Institucional del Ministerio Público Fiscal de la Nación, que busca regular expresamente el uso de videoconferencia en dicho Estado, incorporando los artículos 246, 382 bis y 384 bis, como también, modificando los artículos 355, 359 y $39 \mathrm{I}$.

Sin perjuicio de la citada legislación, que incluye el uso de videoconferencia con fines judiciales de manera expresa, se sustenta el uso de ésta en que «constituye una forma de practicar la contradicción, de materializar el derecho de confrontación y, por lo tanto, un modo de ejercer el derecho a la defensa en juicio».

Todos estos argumentos han sido recogidos en cierta manera por la jurisprudencia de los Tribunales Superiores de Justicia, por ejemplo, en el caso en que:

la Cámara Federal de Mar del Plata ha tenido oportunidad de expedirse al respecto el II de abril de 2005 , en el marco de un recurso de apelación interpuesto por el representante del Ministerio Público Fiscal contra la decisión de primera instancia que había denegado la solicitud de recibir una declaración indagatoria en el trámite de solicitud de asistencia jurídica requerida por un juez penal de sentencia de la República del Paraguay.

El tribunal —integrado por los doctores Ferro y Tazza - consideró

25. Ley 26.200, que incorpora al Ordenamiento Jurídico Interno de Argentina, el estatuto de la Corte Penal Internacional.

26. Ley 25.632, que incorpora al Ordenamiento Jurídico Interno de Argentina, la Convención contra la Delincuencia Organizada Internacional. 
que la recepción de la declaración indagatoria solicitada deviene una medida procesal que se halla incluida en la asistencia jurídica que la Nación se ha comprometido a prestar en el marco de los distintos instrumentos que reglan la materia, analizando el artículo I7 en función del art. 2 Protocolo de Asistencia Mutua en Asuntos Penales entre los Estados Parte del Tratado de Asunción, como también que robustecen la amplia concepción que se propugna y las disposiciones de la Ley de Cooperación Internacional en Materia Penal 24.767 (LA i997-A-29), aplicables como norma supletoria [con lo que finalmente la autoriza].

Bolivia..$^{27}$ En este caso, no existe legislación que prevea expresamente la utilización de la videoconferencia en materia de cooperación internacional ni en materia local. Sin embargo, en el último de los casos,

al referirse a los medios de prueba y libertad probatoria, la norma procedimental penal establece que el Juez admitirá como medios de prueba todos los elementos lícitos de convicción que puedan conducir al conocimiento de la verdad histórica del hecho, de la responsabilidad y de la personalidad del imputado. Pudiendo utilizarse otros medios además de los previstos en este libro (Código de Procedimiento Penal), hecho que abre la posibilidad y permisibilidad de utilizar la herramienta técnica de la videoconferencia. Al respecto existe un instructivo emitido por la máxima autoridad del Ministerio Público por el que se instruye la recepción de declaración de peritos por videoconferencia aplicada a casos y procesos penales en el ámbito nacional.

En cuanto al equipamiento técnico, si bien el Ministerio Público no cuenta con los dispositivos necesarios para practicarla, se prevé la posibilidad de recurrir a empresas privadas que ofrezcan el servicio, aunque hasta abril del año 2009 (fecha de respuesta del cuestionario), no se había realizado esta operación, ni tampoco recibido o solicitado dicha diligencia en el marco de la cooperación internacional, por lo que tampoco existe jurisprudencia respectiva.

En este sentido, se expresa que, sin perjuicio de los tremendos beneficios que conlleva esta práctica, sus posibles debilidades se enmarcan en

27. Cuestionario de Salvador de Bahía sobre Videoconferencia, respondido por Abdiel Adin Andadre Urdinica, Fiscal de Materia, Coordinador en Cooperación Internacional y Extradiciones del Ministerio Público de Bolivia. 
la imposibilidad, por parte de dicho Ministerio Público, de contar con el equipamiento técnico en todos los distritos.

Brasil. ${ }^{28}$ Por su parte, Brasil permite de manera expresa esta práctica, ${ }^{29}$ y su Ministerio Público cuenta con los medios técnicos para realizar videoconferencias, tanto en el ámbito nacional como en el internacional, utilizando respectivamente, tecnología IP e ISDN, y en los territorios que no cuentan con dichos dispositivos, deben ser contratados mediante licitación pública, o en determinados casos de suma urgencia, por licitación privada. Asimismo, su frecuencia de uso es más importante a nivel estadual, y hasta abril del presente año (2009) se habían realizado 3.6I9 audiencias mediante videoconferencia.

Respecto de la jurisprudencia, se señala que existen precedentes contradictorios respecto de la utilización del sistema de videoconferencia en el marco de la justicia penal, por donde la mayor parte de los precedentes son contrarios a esta práctica, se deben a la falta de argumentación por parte de los requirentes. En este sentido, en el área internacional, existen precedentes de requerimientos con resultados positivos, y sin embargo se han producido inconvenientes respecto del sistema utilizado, ya que en la mayoría de los territorios existe sistema con tecnología IP, mientras que en el ámbito europeo se trabaja con tecnología ISDN, siendo ésta una de las debilidades del sistema según el emisor de las respuestas, además de posibles problemas técnicos, como, por ejemplo, fallas en imagen y sonido.

Sin embargo, se estima que, sin duda, el sistema de videoconferencia es más económico, más rápido y que no afecta los principios del debido proceso. Siendo estos puntos los que se aconseja fundamentar siempre en la solicitud de la diligencia, se recalca también la importancia de que el Mercosur adopte las medidas para actualizar la legislación y así permitir de manera expresa la práctica de videoconferencia.

Colombia. ${ }^{30}$ La Fiscalía, a nivel nacional, cuenta con siete equipos de

28. Cuestionario de Salvador de Bahía sobre Videoconferencia, respondido por Vladimir Aras, Procurador de la República de Brasil (Fiscal Federal).

29. Art. 2 I7 del Código Procesal Penal, sólo en caso de situaciones particulares que pudieren afectar la veracidad de una declaración.

30. Cuestionario de Salvador de Bahía sobre Videoconferencia, respondido por Laura Benedetti Roncallo y Aydaluz Segrera Alarcón, asesoras de la Dirección de Asuntos Internacionales de la Fiscalía General de la Nación de Colombia, y revisado por Luis González León, Fiscal Jefe de la Unidad de Justicia y Paz. 
videoconferencia que van rotando a los diferentes lugares de Colombia, y que si bien se utilizan con tecnología IP, también soportan el uso de ISDN.

Respecto de la frecuencia de uso, al interior del país, a través de la red Fiscatel (que es la intranet nacional de la Fiscalía General de la Nación) se utiliza con frecuencia la videoconferencia, especialmente en aplicación de la Ley 975 de 2005 sobre reintegración a la vida civil de guerrilleros, para transmitir las versiones de las personas que se encuentren en lugares donde se concentran las víctimas de su accionar delictivo.

También se han realizado videoconferencias con otros países como Holanda y España, por solicitudes elevadas por los mismos. Actualmente la Fiscalía de Colombia se encuentra trabajando conjuntamente con Colombia Telecomunicaciones S.A., para convenir el servicio internacional de videoconferencia a fin de continuar la dinámica de los procesos iniciados a las personas extraditadas a los Estados Unidos de América y postuladas a la Ley de Justicia y Paz.

A su vez, respecto de la legislación existente, la videoconferencia está establecida entre otros en los artículos 386 del Código de Procedimiento Penal, "Impedimento del testigo para concurrir», y 486, referente al traslado de testigos y peritos. Asimismo, su uso se encuentra reglamentado mediante acuerdo 2 I 4 de octubre I de 2003, proferido por la Sala Administrativa del Consejo Superior de la Judicatura.

En el ámbito internacional, Holanda requirió a la Fiscalía General de la Nación en el sentido de lograr una videoconferencia con un testigo que se encontraba en Colombia. Se llevó a cabo la diligencia solicitada en un plazo de dos días y la comunicación se dio en óptimas condiciones.

Por lo anterior, es que se considera a la videoconferencia como un medio rápido y efectivo, aunque sin la debida implementación no es necesariamente económico.

Paraguay. ${ }^{31}$ Paraguay adquirió recientemente equipos para videoconferencias que utilizan tecnología IP y, con anterioridad, se recurrió a organismos internacionales, como las Naciones Unidas, habiendo sido utilizados hasta abril del año 2009 en cuatro ocasiones. Si bien no cuenta con regulación expresa, su sustento jurídico sería la libertad probatoria, consagrada en el artículo I73 del Código Procesal Penal.

3 I. Cuestionario de Salvador de Bahía sobre Videoconferencia, respondido por María Magdalena Quiñónez, asistente Fiscal del Ministerio Público de Paraguay. 
En el ámbito de la jurisprudencia, si bien no existen precedentes de tribunales nacionales, si se ha producido cooperación internacional, entre otros casos, en una declaración del 8 de abril de 2003, en la cual «España solicitó la declaración del testigo de un hecho punible de estafa, residente en Paraguay, y con dicha declaración se logró la condena de los inculpados». Cabe señalar al respecto que se trata del "primer caso de declaración testifical mediante el sistema de videoconferencia realizado a través de Internet» (Candia, 2009).

Cabe también recalcar que dicha declaración creó un precedente importantísimo y que causó gran impacto mediático: se señaló que «una videoconferencia que duró unos cuarenta minutos bastó para dar por concluida una instancia judicial que suele llevar semanas (cuando no meses) atravesando burocracias administrativas y diplomáticas». ${ }^{32}$

Presumiblemente, por esta práctica, junto con los posibles altos costos, es que se señala como debilidad del sistema el posible uso indiscriminado, y se recalca que su uso debe ser responsable. Esto, no obstante, de que se reconocen sus cualidades, como la adaptación a las necesidades impuestas en la práctica de los distintos actos procesales y sin afectar los principios de inmediación, publicidad, contradicción y oralidad.

Uruguay. ${ }^{33}$ En este caso, el Ministerio Público no cuenta en el ámbito institucional con esta herramienta, debiendo brindar el servicio la empresa estatal de telecomunicaciones Antel, que dispone de tecnología IP e ISDN, existiendo salas especialmente habilitadas para la prestación de este servicio. Asimismo, dicha herramienta se utiliza a nivel nacional sólo en el ámbito de la capacitación.

Respecto a su regulación, el uso de esta herramienta no está mencionado de forma expresa en la legislación nacional y, sin embargo, se puede fundamentar su uso en el art. I73 del Código Procesal Penal, que admite «cualquier otro medio de prueba no prohibido por ley, que pueda utilizarse aplicando analógicamente las normas que disciplinan a los expresamente previstos».

32. Diario Clarín, disponible en <http://edant.clarin.com/diario/2003/04/o9/t-542338. htm>.

33. Cuestionario de Salvador de Bahía sobre Videoconferencia, respondido por Enrique Rodríguez Martínez, Fiscal Letrado Nacional, con la supervisión de la Fiscalía de Corte y Procuraduría General de la Nación. 
Se debe agregar que Uruguay ratificó y aprobó, por ley de la Nación, diversas normas supranacionales que prevén la utilización de la videoconferencia; por ejemplo, las leyes I7.86I (Convención de la ONU de Nueva York, contra la Delincuencia Organizada Transnacional) y la ley I 8.056 (Convención de la ONU de Mérida, contra la Corrupción), y asimismo se puede tener como base el Protocolo de San Luis, ley I7.I45, arts. I literal K), 2, 6, I3, I7 y I 8, además del espíritu que posee toda solicitud de cooperación jurídica internacional, que no es otro que el de facilitar y no poner obstáculos a la cooperación, para así combatir más eficazmente a la delincuencia transnacional, respetando, por supuesto, el orden público del país. Por otra parte, pueden invocarse, como normas análogas, los artículos 222 y 224 del Código del Proceso Penal referidos a la recepción de testimonio fuera del lugar del juzgado que tramita la causa o investigación penal, y sin embargo no se han recibido solicitudes internacionales.

Venezuela. ${ }^{34}$ El Ministerio Público de Venezuela cuenta con las herramientas para realizar videoconferencias a través del sistema IP, y recurriendo a empresas privadas cuando se requiere el sistema ISDN, utilizándola de manera interna una o dos veces por mes, y habiéndola utilizado en materia de cooperación internacional con Holanda, Italia y Guyana.

No cuenta con un cuerpo legal que se refiera expresamente al tema, pero se puede levantar una argumentación coherente con los principios del proceso penal, en virtud del principio de libertad de prueba (I98 CPP) regente en Venezuela, como del artículo 340 del CPP, y a su vez con la Ley de Protección de Víctimas y Testigos. Asimismo, Venezuela es parte de la Convención de las Naciones Unidas contra la Delincuencia Organizada Transnacional, la que, como se menciona con anterioridad en la presente investigación, dispone la utilización de esta herramienta como medio de cooperación internacional.

Finalmente, en el ámbito de la jurisprudencia «es pertinente citar el criterio de la Sala Constitucional del Tribunal Supremo de Justicia, respecto a dicho principio, expresado en la decisión I 57I, de fecha 22 de agosto de 200I, con ocasión de la acción de amparo interpuesta por la

34. Cuestionario de Salvador de Bahía sobre Videoconferencia, respondido por Juan Carlos Cabello Mata, Coordinador de Asuntos Internacionales del Ministerio de Venezuela. 
Asociación Civil Deudores Hipotecarios de Vivienda Principal contra la Superintendencia de Bancos y Otros Institutos de Crédito y el Consejo Directivo del Instituto para la Defensa y Educación del Consumidor y el Usuario (caso 'Créditos Mexicanos')», que en sus considerandos I. ${ }^{\circ} \mathrm{y}$ 2. ${ }^{\circ}$ señala:

Considera la Sala que el principio de inmediación en su fase clásica: presencia del sentenciador en la incorporación (evacuación) de las pruebas, puede tener dos manifestaciones o grados:

i) Que el juez presencie personalmente los actos de recepción de la prueba, en los cuales - de acuerdo a lo que se disponga en la ley- puede intervenir, no sólo dirigiéndolos, sino realizando actividades probatorias atinentes al medio (interrogatorios, etcétera).

ii) Que el juez no presencie personalmente in situ la evacuación de la prueba, pero sí la dirige de una manera mediata, utilizando técnicas y aparatos de control remoto, que le permiten aprehender personalmente los hechos mediante pantallas, censores, monitores o aparatos semejantes (videoconferencias, por ejemplo), coetáneamente a su ocurrencia.

\section{BREVE REFERENCIA AL CASO CHILENO ${ }^{35}$}

El Ministerio Público de Chile tiene las herramientas técnicas para realizar videoconferencias a cualquier parte del país y del mundo, con conexiones de tecnología IP como ISDN, aunque suele trabajarse más con ISDN por la nitidez de la información. Aún así, cuando en el país desde el cual se desea realizar una videoconferencia no existe una contraparte institucional que tenga equipos, o habiéndola ésta no es la encargada según su legislación interna de participar de la videoconferencia, en esos casos se recurre al arriendo del servicio procurando la utilización de consorcios que tengan sucursales y/o redes de apoyo mundial en muchos países.

35. Si bien en otra oportunidad nos referimos más en extenso al caso de la evolución que ha experimentado la legislación relativa a la videoconferencia en el proceso penal chileno y su utilización como medio de cooperación internacional (Albornoz y Magdic, 20I2), las siguientes referencias se extraen de las respuestas al Cuestionario de Salvador de Bahía entregadas por el entonces subdirector de la Unidad Especializada de Cooperación Internacional y Extradiciones (UCIEX) y coautor del presente artículo, Marko Magdic, en el año 2009. 
Respecto de la frecuencia a nivel nacional, esto es, videoconferencias en las que tanto el origen como el destino de la señal se encuentran en Chile, se realizan un promedio de dos diarias (un aproximado total de 480 videoconferencias anuales). A nivel internacional, esto es, videoconferencias en las que el origen o destino de la señal se encuentran fuera de Chile, se realizan un promedio de siete anuales.

Por otra parte, en Chile no existe legislación que trate la videoconferencia como medio de cooperación internacional de manera expresa. Sin embargo, su factibilidad puede extraerse del análisis de preceptos legales nacionales e internacionales vinculantes.

Así, el artículo 329 del Código Procesal Penal, cuyo inciso final fue agregado mediante reforma legal en noviembre de 2005 , señala que:

Los testigos y peritos que, por algún motivo grave y difícil de superar no pudieren comparecer a declarar a la audiencia del juicio, podrán hacerlo a través de videoconferencia o a través de cualquier otro medio tecnológico apto para su interrogatorio y contrainterrogatorio. La parte que los presente justificará su petición en una audiencia previa que será especialmente citada al efecto, debiendo aquéllos comparecer ante el tribunal con competencia en materia penal más cercano al lugar donde se encuentren.

Cuando esta norma exige la comparecencia ante el tribunal más cercano al lugar donde se encuentren los declarantes se refiere a la declaración por videoconferencia nacional. La intervención del tribunal tiene razón de ser por cuanto éste actúa como ministro de fe, velando no sólo por la identidad del declarante y por la participación libre y voluntaria del mismo, sino que también como garante de que el testigo que aún no ha declarado no presencie la declaración del que lo antecedió.

Desde luego que respecto de las videoconferencias internacionales no es dable exigir la intervención del juez extranjero, pues muchas veces éstos no participan en su realización, como en México, por ejemplo. Ocurrirá otras veces que algunos jueces sean de países que no hablen español, por lo que no siempre su calidad de ministro de fe pueda ser bien cumplida. Si bien no se trata de descartar la participación de jueces, debe considerarse como una alternativa, mas no la única forma mediante la cual se presta declaración.

Es por eso que en todas las videoconferencias internacionales se ha 
solicitado a los cónsules chilenos como ministros de fe para los efectos ya descritos, incorporando a los jueces extranjeros sólo cuando la legislación del país requerido así lo ha exigido como condición para realizar la videoconferencia, lo cual ha ocurrido en aquellos casos en los que los declarantes han sido funcionarios públicos extranjeros.

Por su parte, el artículo I 92 del Código Procesal Penal, referente a la declaración anticipada, señala que:

Si el testigo se encontrare en el extranjero y no pudiere aplicarse lo previsto en el inciso final del artículo I90 [traslado], el fiscal podrá solicitar al juez de garantía que también se reciba su declaración anticipadamente. Para ese efecto, se recibirá la declaración del testigo, según resultare más conveniente y expedito, ante un cónsul chileno o ante el tribunal del lugar en que se hallare.

No ha habido inconveniente para aplicar este artículo en declaraciones prestadas durante la misma audiencia de juicio oral, toda vez que ello iría en directo beneficio del respeto a las normas y garantías del debido proceso. Es decir, si se permite la intervención de un cónsul para asegurar la declaración de un testigo que está en el extranjero antes de la realización de juicio, en las fases tempranas de la investigación, cuando probablemente las partes tengas menos medios para contrainterrogar al testigo, y si se permite que luego esa declaración sea grabada e introducida de esa manera en el juicio oral mediante exhibición de video, entonces parece altamente deseable que el testigo pueda declarar ante el cónsul durante la misma audiencia de enjuiciamiento, con la posibilidad de ser interrogado y contrainterrogado «en vivo y directo» sin necesidad de estar viendo video.

Toda vez que un cónsul no puede tomar declaración en el extranjero tanto porque podría no tener la preparación jurídica como porque su accionar afectaría la soberanía del otro Estado, vulnerando las Convenciones de Viena sobre Relaciones Diplomáticas y Consulares, la única forma de entender este artículo - y así lo han hecho varios fallos- es que la declaración se preste por videoconferencia y se reciba ante el cónsul (no la toma el Cónsul, la recibe), para que produzca efectos en tiempo real ante el tribunal en Chile.

Sería imposible pensar que el cónsul chileno o un tribunal extranjero tomen declaración para un juicio oral en Chile. Imaginemos sólo las 
dificultades que se presentarían si un fiscal o defensor chileno objetaren alguna pregunta o forma de proceder del tribunal extranjero o cónsul. ¿Conforme a qué normas se resolvería? ¿Qué ocurriría si la decisión del cónsul o del tribunal es contraria a los principios más básicos del proceso penal chileno? ¿O qué pasaría si el tribunal extranjero admite preguntas sugestivas a los testigos que presenta una misma parte?

Por tanto, la fundamentación jurídica para viabilizar una declaración mediante videoconferencia en Chile estaría dada tanto por los artículos 329 y 192 del Código Procesal Penal relacionados con los artículos 297 y 323 del mismo cuerpo legal que consagran la libertad probatoria, admitiendo todo medio apto para producir fe.

Por otra parte, la jurisprudencia que existe en Chile al respecto se debe a que cada vez que se realiza una videoconferencia durante un juicio oral es porque ésta ha sido previamente autorizada por el tribunal, de manera que en el fallo, sea absolutorio o condenatorio, desde el momento en que pondera la declaración del testigo, víctima, perito o imputado, valida automáticamente la videoconferencia como medio de declaración.

Es importante destacar un fallo de la Sala Penal de la Exma. Corte Suprema de Justicia de Chile, el que hace un análisis detallado acerca de la admisibilidad de la videoconferencia, señalando principalmente que la comparecencia mediante videoconferencia es análoga a la comparecencia personal, y produce prácticamente los mismos efectos jurídicos. ${ }^{36}$

Finalmente, cabe señalar que el Ministerio Público de Chile ha solicitado la toma de declaraciones por videoconferencia en el marco de la cooperación internacional a países como Australia, Nueva Zelanda, Panamá, Reino Unido, España, Holanda, Filipinas, Italia y Rumania entre otros, mientras que ha recibido solicitudes de países como España y Costa Rica.

36. Dictado con fecha II de agosto de 2003 , en el que la Sala Penal de la Corte Suprema se pronuncia sobre un recurso de nulidad que buscaba anular una sentencia del Tribunal del Juicio Oral en lo Penal de Calama, Rol Único 02000I I 27-I, Rol Interno del Tribunal I3-2003, que condenaba a un imputado por delito de violación. Analizado en Albornoz y Magdic (201 2: 59). 


\section{CONCLUSIONES Y ESTADO DE LA CUESTIÓN}

Luego de los antecedentes expuestos, parece factible concluir que la videoconferencia es una herramienta cuya utilización se encuentra permitida por algunos de los más importantes tratados internacionales de derechos humanos aplicables al proceso penal, los que, como sabemos, nos entregan el marco dentro del cual debe desenvolverse toda la normativa y actividad jurídica nacional. En ese sentido, en el derecho comparado se reconocen las virtudes de la utilización de la videoconferencia, que puede significar grandes avances en materia de persecución y proceso penal.

En ese sentido, del estudio de la legislación, doctrina y jurisprudencia existentes en distintos países del Cono Sur, como Argentina, Bolivia, Brasil, Colombia, Paraguay, Uruguay y Venezuela, además, por supuesto, de la necesaria referencia al derecho nacional, podemos concluir que la videoconferencia como herramienta de cooperación internacional, es un mecanismo generalmente aceptado de manera expresa dentro de los sistemas procesales penales de la región, y aun en aquellos en que no existe referencia legislativa expresa, ésta se puede realizar de todas formas, sea mediante la interpretación de los principios fundantes del debido proceso, como también a partir de un análisis sistemático que haga referencia a las normas supranacionales.

Por su parte, en Chile, si bien la ley no ha reconocido expresamente la utilización de la videoconferencia como instrumento de cooperación internacional de manera expresa, ésta se puede utilizar en virtud de la interpretación de principios básicos del proceso penal, que apuntan a la mayor y mejor protección del derecho al debido proceso.

En el mismo contexto, parece pertinente advertir que si la videoconferencia puede servir de utilidad en el marco del proceso penal, el cual por sus características propias exige el más elevado estándar de respeto y protección a principios como el de inmediación y contradicción, perfectamente podría utilizarse en otras ramas del derecho cuyos procedimientos son similares.

Finalmente, uno de los objetivos del presente trabajo es precisamente ése, en virtud del viejo aforismo que afirma que «quien puede lo más puede lo menos», y aun cuando la idea se plantea de manera exigua y tangencial, imaginemos como la videoconferencia podría ser un adelanto que, teniendo como base la discusión y aceptación que ha tenido en 
el ámbito del proceso penal, pudiese «exportarse» en cuanto a su aplicación a áreas tales como el derecho de familia y el derecho internacional en general.

\section{REFERENCIAS}

Albornoz, Jorge y Marko Magdic (20I2). "La videoconferencia en el proceso penal chileno. Evolución en su utilización como medio de cooperación internacional». Nexus Iuris (Centro de Estudios del Derecho de Arica), núm. I: 52-77.

Candia, Rubén (2009). Palabras de bienvenida al I Taller sobre Uso de la Videoconferencia en la Cooperación Jurídica internacional, en su calidad de Fiscal General del Estado de Paraguay, el día 28 de abril, en la ciudad de Asunción, Paraguay.

Chahuán, Sabas (2007). Manual del nuevo procedimiento penal. Santiago: LexisNexis.

De la Mata, José (2003). "La utilización de la videoconferencia en las actuaciones judiciales». Ponencia presentada en el Seminario de Formación Continuada del CGPJ, realizado en Madrid, del I7 al I9 de septiembre.

Delmas-Marty, Mireille (2000). Procesos penales de Europa (Alemania, Inglaterra y País de Gales, Bélgica, Francia, Italia). Traducción de Pablo Morenilla Allard. Zaragoza: Edijus.

Godoy, María Elena (2009). «Breves notas sobre videoconferencia». Documento de Trabajo para la Reunión Especializada de Ministerios Públicos del Mercosur. Inédito, en poder de los autores.

Granadillo, Nancy (2006). «Marco legal internacional contra la delincuencia organizada». Ponencia en el Tercer Encuentro Anual de Criminología efectuado en la Universidad Católica Andrés Bello, Caracas, Venezuela.

Mehrabian, Albert (1972). Silent Messages: Implicit Communication of Emotions and Attitudes. California: Wadsworth.

Ministerio Público de Chile, División de Atención a Víctimas y Testigos (2003). La víctima y el testigo en la Reforma Procesal Penal. Prólogo del fiscal nacional Guillermo Piedrabuena. Santiago: Fallos del Mes. 
Monterde, Francisco (2006). «El proceso de introducción de las nuevas tecnologías en el ejercicio de la función jurisdiccional». Cuadernos Constitucionales de la Cátedra Fadrique Furió Ceriol (Departamento de Derecho Constitucional y Ciencia Política y de la Administración de la Universitat de Valencia), núm. 56: 25-59. Valencia: UV.

Nevado, María Teresa (20I2). «Reflexión sobre la actualidad de la declaración electrónica en el proceso penal español. Especial consideración del proceso con menores». Revue Droit International, Commerce, Innovations et Développement (DICID), núm. I: 7-I 5 .

Piedrabuena, Guillermo (2005). Oficio F.N. I04, que informa sobre la ratificación y promulgación de la Convención de Palermo, Santiago.

TAVOlaRi, Raúl (2003). Informe en derecho, solicitado por el fiscal nacional de Chile, Guillermo Piedrabuena Richard, sobre videoconferencia. Viña del Mar.

Tirado, Jesús (s/f). «Videoconferencia y equipos conjuntos de investigación». Material elaborado por el autor en su calidad de Fiscal en la Unidad de Apoyo al Fiscal General de España.

VÁsquez, Santiago Raúl (2009). «Fundamentos de la videoconferencia y su implementación en el Ministerio Público del Paraguay». Fiscalía General del Estado, Dirección de Informática, Administración de Redes y Sistemas. Documento de trabajo presentado en el Primer Taller sobre Uso de la Videoconferencia en la Cooperación Jurídica Internacional, en el marco de la Reunión Preparatoria de la VII Reunión de Ministerios Públicos del Mercosur, celebrada el 28 de abril de 2009, Paraguay.

\section{SOBRE LOS AUTORES}

Jorge Albornoz Barrientos es egresado de la Facultad de Derecho de la Universidad Nacional Andrés Bello. Se ha desempeñado como ayudante y colaborador en investigación para el doctor Tomás Vial Solar y como ayudante de la cátedra de Derechos Fundamentales en la Universidad Nacional Andrés Bello. Su correo electrónico es <jor.albornoz@icloud.com>.

Marko Magdic es abogado, licenciado en Ciencias Jurídicas y Sociales de la Universidad Diego Portales. Se desempeñó como Subdirector de la Unidad de Cooperación Internacional y Extradiciones de la Fiscalía 
Nacional de Chile y como Jefe del Departamento de Crimen Organizado y Cooperación Internacional del Ministerio de Interior y Seguridad Pública de Chile. Su correo electrónico es <mmagdic@step-c.com>.

Este trabajo fue recibido el 22 de mayo de 2013 y aprobado el $2 \mathrm{I}$ de junio de 2013 . 